JOURNAL OF INFORMATICS AND TELECOMMUNICATION ENGINEERING

Available online http://ojs.uma.ac.id/index.php/jite

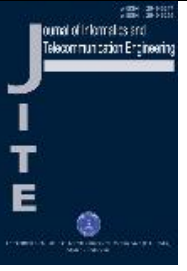

\title{
Pengenalan Pola Logo Merk Mobil dengan Menggunakan Algoritma Deteksi Tepi Prewitt dan Jaringan Saraf Tiruan Backpropagation
}

\section{Introduction of Car Brand Logo Patterns by Using Prewitt Edge Detection Algorithms and Artificial Neural Networks Backpropagation}

\author{
Sudirman*, Muhammad Yudha Syuhada \\ STMIK \&AMIK Logika Medan, Universitas Sumatera Utara
}

*E-mail Korespondensi : sudirman@merahputih.id

\begin{abstract}
Abstrak
Pada jurnal ini, akan dibahas penggunaan algoritma deteksi tepi Prewitt dan jaringan saraf tiruan Backpropagation sebagai bentuk pengenalan terhadap pola citra logo mobil. Inputan ke dalam jaringan saraf berupa binary image yang telah mengalami deteksi tepi dengan algoritma Prewitt kemudian pola akan dikenali pada jaringan saraf tiruan Backpropagation. Jurnal ini mendiskusikan bagaimana kemampuan kedua algoritma dikombinasikan untuk menentukan logo suatu mobil dengan data yang relatif kecil.
\end{abstract}

Kata kunci: Prewitt, Edge Detection, Neural Network, Backpropagation

\section{Abstract}

In this journal, we will discuss the use of detection algorithm. Presets and artificial neural networks Backpropagation as a form of recognition of car logo logo patterns. Input into a neural network with a binary image that has been hearing with the Prewitt algorithm and then the pattern will be recognized on the backpropagation neural network. Problem analysis with relatively small data. 


\section{PENDAHULUAN}

Pengenalan pola menggunakan jaringan saraf tiruan merupakan ilmu yang berkembang dengan pesat. Banyaknya metode serta kebutuhan dari pengguna akan kecerdasan komputasi dalam menentukan pola, mendorong ilmu ini untuk terus berkembang.

Algoritma Prewitt merupakan salah satu algoritma deteksi tepi (edge detection) yang cukup mudah untuk diimplementasikan dan memiliki keakuratan yang cukup baik sedangkan Backpropagation merupakan satu dari sekian banyak algoritma pelatihan jaringan saraf tiruan[1]. Dengan menggabungkan kedua algoritma ini, diharapkan akan memberikan hasil yang cukup akurat.

\section{METODE PENELITIAN}

Pada jurnal ini, akan dilakukan pengenalan pola logo mobil pada jaringan dimana terdapat sebelas logo mobil yang berbeda yang akan dilakukan pelatihan dan kemudian jaringan akan diuji dengan logo-logo mobil pengujian akan dilakukan sebanyak delapan kali dimana semuanya akan diuji dari gambar yang berbeda dari yang dilatihkan.

Kita akan mendiskusikan bagaimana kemampuan jaringan akan mengenali pola. Logo merk mobil yang dilatih adalah BMW, Cadillac, Ford, Infiniti, Kia, Mazda, Mercedez Benz, Subaru, VW dan Toyota.

\section{Algoritma Deteksi Tepi Prewitt}

Dalam pengenalan pola pada jaringan saraf tiruan, algoritma deteksi tepi Prewitt akan digunakan sebagai feature extraction yang akan merubah citra logo mobil menjadi citra biner yang sudah terdeteksi tepiannya.
Pada umumnya cara kerja deteksi tepi Prewitt mirip dengan cara kerja deteksi tepi Sobel, namun perbedaannya hanya terletak pada template yang tidak menggunakan nilai yang sama[2].

Operator Prewitt menggunakan dua matriks berukuran $3 \times 3$ dengan nilai sebagai berikut:

$$
\begin{aligned}
\mathbf{G}_{\mathbf{x}} & =\left[\begin{array}{ccc}
-1 & 0 & +1 \\
-1 & 0 & +1 \\
-1 & 0 & +1
\end{array}\right] * \mathbf{A} \\
\mathbf{G}_{\mathbf{y}} & =\left[\begin{array}{ccc}
-1 & -1 & -1 \\
0 & 0 & 0 \\
+1 & +1 & +1
\end{array}\right] * \mathbf{A}
\end{aligned}
$$

Dimana A merupakan nilai dari citra yang akan dilakukan deteksi tepi. Pada jurnal ini, nilai ambang pada deteksi tepi Prewit adalah 128.

\section{Algoritma Backpropagation}

Algoritma Backpropagation bekerja melalui koreksi bobot pada jaringan saraf tiruan. Bobot yang awalnya dipilih secara acak antara 0 hingga 1 kemudian akan terus dikoreksi hingga maksimum epoh ataupun nilai eror sudah lebih kecil dari target eror. Adapun pseudocode algoritma Backpropagation adalah sebagai berikut[3]:

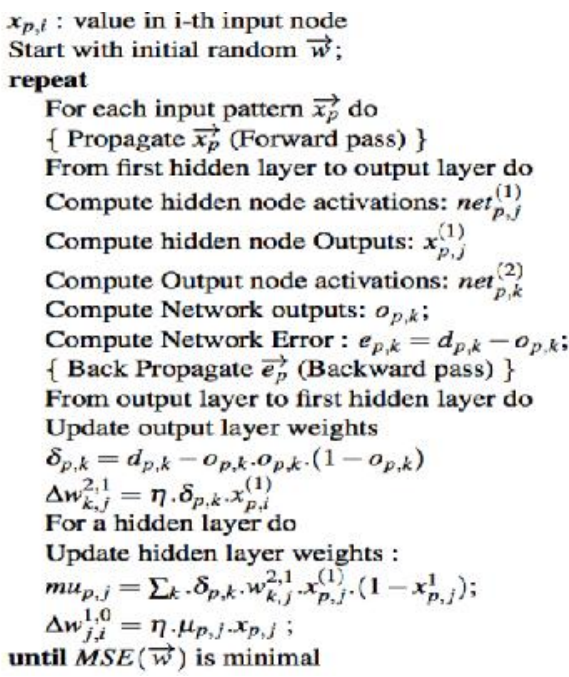


Arsitektur jaringan saraf yang akan dibangun pada jurnal ini adalah memiliki dua inputan yang diambil dari setiap dua pixel kemudian dengan satu bias dan empat hidden layer yang ditunjukkan sebagai berikut:

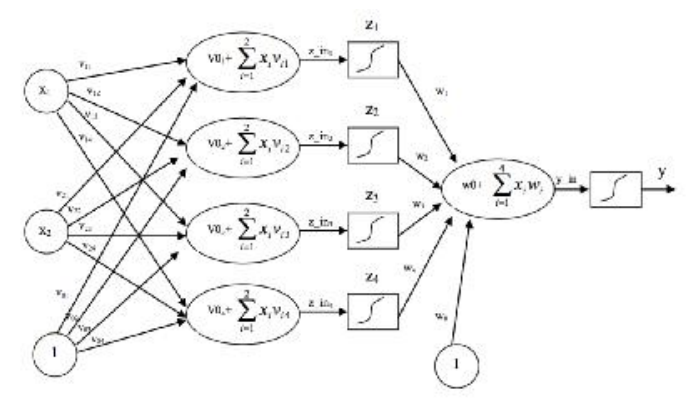

Gambar.1. Arsitektur Jaringan

Pada proses pelatihan, nilai epoh maksimal adalah 1000 dan target eror $=$ 0.01 dengan learning rate $=0.5$.

\section{HASIL DAN PEMBAHASAN}

Pengujian akan dilakukan dengan melakukan training pada jaringan saraf dengan data sebagai berikut:

Tabel.1. Data Hasil Training

\begin{tabular}{|l|l|l|}
\hline \multicolumn{1}{|c|}{ Nama } & MSE & \multicolumn{1}{l|}{ Waktu $(\mathrm{ms})$} \\
\hline BMW & $\mathbf{0 . 0 9 3 2 5}$ & 270990 \\
\hline Cadillac & $\mathbf{0 . 4 5 5 1 4}$ & 269306 \\
\hline Ford & 0.20657 & 266699 \\
\hline Infiniti & 0.34752 & 278177 \\
\hline Kia & 0.36704 & 269771 \\
\hline Mazda & 0.24023 & 271098 \\
\hline Mercedez & 0.31762 & 273517 \\
\hline Subaru & 0.21215 & 49293 \\
\hline VW & 0.02791 & 278251 \\
\hline Toyota & 0.07109 & 280459 \\
\hline
\end{tabular}

Pada melakukan training, program dibuat dengan menggunakan bahasa Java dan IDE NetBeans, spesifikasi komputer yang digunakan adalah MacBook Pro dengan processor i5 dan RAM 8 GB. Resolusi gambar adalah 640x480 pixel.

Setelah melakukan training maka selanjutnya adalah tahapan pengujian jaringan dengan menggunakan 8 gambar logo mobil dimana sebagian logo adalah logo yang sama yang digunakan pada saat training namun dengan warna dan gambar yang berbeda.

Tabel.2. Tabel Data Recognition

\begin{tabular}{|l|l|l|}
\hline Nama & Dikenali & Hasil \\
\hline Ford & Ya & Ford \\
\hline Porsche & Tidak & \\
\hline VW & Ya & Toyota \\
\hline Tesla & Tidak & \\
\hline Mazda & Tidak & \\
\hline BMW & Ya & Mercedez \\
\hline Honda & Tidak & \\
\hline
\end{tabular}

Dari hasil recognition tersebut dapat dilihat bahwa jaringan mampu mengenali sebagian besar logo yang sudah dilatihkan namun masih ada kesalahan pada menentukan hasil. Dari 8 logo mobil yang sudah diuji, jaringan hanya mampu mengenali dengan tepat 1 logo saja, sedangkan 3 logo yang dikenali lainnya memiliki hasil yang salah, 4 logo yang tidak diuji juga diprediksi dengan tepat sebagai logo yang tidak dikenali namun terdapat 1 logo yaitu logo Mazda yang merupakan kesalahan pengenalan.

Nilai threshold yang digunakan ketika melakukan pengujian adalah sama dengan nilai target eror yaitu 0.01 sehingga apabila nilai selisih MSE dari gambar uji dengan gambar training lebih besar dari 0.01 maka akan dianggap tidak dikenali. 


\section{SIMPULAN}

Dari hasil pengujian, dapat
disimpulkan bahwa jaringan dengan arsitektur di atas dapat digunakan dalam mengenali logo-logo mobil, namun kita harus menambah data training agar hasil pada pengenalan logo bisa lebih baik dimana saat pengujian dilakukan, dari 4 logo hanya terdapat 1 logo saja yang diprediksi tepat, 2 logo dapat dikenali namun tidak tepat dan 1 logo salah dalam pengenalan. Pada logo-logo yang belum ditraining, jaringan dapat melakukan pengenalan dengan baik dimana semua logo tersebut tidak dikenali.

Pada proses training, nilai rata-rata training untuk setiap logo adalah 25076 ms.

\section{DAFTAR PUSTAKA}

Herlan Silaban, Muhammad Zarlis, Sawaluddin, "Analysis of Accuracy and Epoch on Backpropagation BFGS Quasi-Newton", Intenational Conference on Information and Communication Technology, 2017.

Li Bin, Mehdi Samiei yeganeh, "Comparison for Image Edge Detection Algorithm",IOSR Journal of Computer Engineering (IOSRJCE) Volume 2, Issue 6, 2012.

Kesari Verma, Ligendar Kumar Verma, Priyanka Tripathi, "Image Classification using Backpropagation Algorithm", Journal of computer Science and Software Application, Volume1, Number 2, December 2014. 